\title{
La memoria y la construcción de lo subjetivo'
}

\section{Memory and the Construction of Subjectivity}

Alexis V. Pinilla Díaz

\section{Resumen}

En el presente artículo se hace una reflexión teórica sobre la génesis y el desarrollo de la memoria, como categoría sociológica, destacando el importante papel político que tienen las luchas por la memoria en la reconstrucción del pasado y el presente. Finalmente se propone que la memoria, junto a la acción colectiva, es una categoría fundamental para comprender los procesos de constitución de las subjetividades contemporáneas.

\section{Palabras clave}

Memoria, historia, pasado-presente, acción colectiva, subjetividad.

\section{Abstract}

In this paper we do a theoretical consideration about the genesis and development of memory, as a sociological category, by emphasizing the important political role that fights of memory have by building the past and the present. Finally it is proposed that memory attached to the collective action is a fundamental category to understand the process of constitution of the actual subjectivities.

Keywords

Memory, history, past-present, collective action, subjectivity.

Artículo recibido el 16 de mayo 2011 y aprobado el 19 de agosto de 2011

1 Este artículo hace parte del trabajo de tesis doctoral "Memorias de la acción colectiva del magisterio en Colombia", adelantada por el autor en el marco del Doctorado Interinstitucional en Educación, sede Universidad Pedagógica Nacional.

2 Profesor Asociado Departamento de Ciencias Sociales. Coordinador Maestría en Estudios Sociales, Universidad Pedagógica Nacional. Correo electrónico: apinilla@pedagogica.edu.co 


\section{Presentación}

Desde hace un par de décadas la memoria se ha consolidado como una categoría analítica central para comprender los procesos históricos y la forma cómo se ha narrado el pasado y presente de nuestras sociedades. Para el caso de América Latina este énfasis en la memoria estuvo relacionado con el regreso a la democracia producto de la caída de los gobiernos militares del Cono Sur. En este contexto la intención fue no dejar en el olvido los crímenes que los dictadores cometieron contra la sociedad civil y recuperar la imagen viva de las víctimas de tales crímenes. Para el caso de Colombia, el recurso a la memoria se ha activado en relación con las víctimas del conflicto armado que ha azotado al país desde la década de los 80. Los hitos anteriores ponen de presente que la memoria es un escenario de disputa para la construcción de proyectos de pasado y futuro, pues como se anota en la clásica obra de George Orwell (1984) «quien domina el presente, domina el pasado; quien domina el pasado, domina el futuro».

\section{Ascendencias de la memoria}

Los estudios sobre la memoria cobraron vigencia durante las dos últimas décadas del siglo anterior. Puede decirse, incluso, que frente a los estudios cronológicos propios de las corrientes históricas tradicionales, la memoria se convirtió en un valioso recurso para darle un significado más amplio al pasado. Este hecho puede llevarnos a pensar nuestra época como un momento de mnemotropismo, entendido por Candau como una coyuntura en la que el regreso a la memoria resulta clave para comprender no sólo nuestro pasado, sino para darle sentido(s) a nuestro presente. Resulta, entonces, que la memoria se constituye en un espacio analítico fundamental para comprender cómo se conforma tanto el tiempo presente, como las subjetividades que habitan en él. Pareciera que, en este punto, la memoria se torna distante de la historia en los siguientes términos:

Si la historia tiende a aclarar lo mejor posible el pasado, la memoria busca más bien instaurarlo, instauración que es inmanente a la memorización en acto. La historia busca revelar las formas del pasado, la memoria las modela, un poco como lo hace la tradición. La primera se preocupa por poner en orden; la segunda está atravesada por el desorden de la pasión, de las emociones y de los afectos. La historia puede venir a legitimar, pero la memoria es fundadora. La historia se esfuerza por poner el pasado a distancia; la memoria busca fusionarse con él (Candau, J., 2001).

Las diferencias entre la memoria y la historia expresadas por Candau son igualmente analizadas por Rossi, quien alude que la historia se centra en la comprensión e interpretación del pasado, por lo cual requiere de una toma de distancia del mismo, mientras que la memoria implica una participación emotiva en el pasado. Así, un estudio sobre la memoria no es un recuento sobre lo que sucedió, sino un análisis de cómo se involucraron los actores sociales en eso que sucedió (Rossi, 2003). Profundizando un poco en el origen de este distanciamiento entre la historia y la memoria, Traverso (2007) sugiere que un momento significativo fue la crisis del historicismo en la década del 60, en donde aparecieron estudios que dieron un papel más protagónico a los sectores subalternos, para lo cual se acudió a fuentes alejadas de los archivos oficiales utilizados tradicionalmente por los historiadores. Para este autor la historia es una representación del pasado, fundada en la distancia, que se pretende objetiva y retrospectiva, mientras que la memoria es afectiva y mágica, por lo cual llena de significado la cotidianidad presente de los sujetos sociales.

No obstante, no sería viable hipostasiar la memoria como recurso ineludible para la comprensión del pasado, limpiándola de cualquier 'contaminación' de la historia oficial. Contrario a ello la memoria, como argumentaré más adelante, es un terreno de disputa en donde la versión oficial de la historia también tiene su lugar, ya que «los recuerdos son constantemente elaborados por una memoria inscrita en el espacio público, sometidos a los modos de pensar colectivos, pero también influidos por los paradigmas científicos de la representación del pasado» (Traverso 2007).

Otro de los riesgos que conllevan los análisis de la memoria es presentado por Sarlo, quien ve con alguna reserva el hecho de que cuando se hable de 
memoria se haga énfasis en los recuerdos y olvidos y no en el entendimiento del pasado. Siguiendo a Susan Sontang (quien anotó que quizás se le asigna demasiado valor a la memoria y un valor insuficiente al pensamiento), Sarlo propone una reconstrucción reflexiva del pasado «desoyendo la amenaza de que, si se examinan los actuales procesos de memoria, se estaría fortaleciendo la posibilidad de un olvido indeseable» (Sarlo, 2005). Así, «el tiempo pasado no es el del testimonio y su dimensión autobiográfica, sino el del análisis de lo que otros narraron y la elaboración de clasificaciones y categorías» (Sarlo, 2005).

Ligado a lo anterior, es necesario pensar con detenimiento de qué manera se establecen las relaciones entre memoria y olvido, aceptando que es muy difícil concebir la una sin el otro, ya que convertir en 'objeto' de memoria algún recuerdo o acontecimiento, implica hacer una selección intencionada de lo que se pretende olvidar. Para Augè,

[...] llevar a cabo el elogio del olvido no implica vilipendiar la memoria, y mucho menos aún ignorar el recuerdo, sino reconocer el trabajo del olvido en la primera y detectar su presencia en el segundo. La memoria y el olvido guardan en cierto modo la misma relación que la vida y la muerte [...] en un caso la muerte se halla ante mí y debo en el momento presente recordar que un día tengo que morir, y en el otro la muerte está tras de mí y debo vivir el momento presente sin olvidar el pasado que habita en él (Augè, 1998).

Reconociendo que, para el caso de este proyecto, la memoria es el lugar desde el cual se analizarán las acciones colectivas del magisterio y los procesos de construcción de la subjetividad de los maestros, es prudente aclarar las relaciones que se entablan entre memoria individual y memoria colectiva, entendiendo que la dialéctica entre la memoria y el olvido se inscribe en un ámbito social de disputas políticas. Así, lo que en un momento histórico específico puede resultar hegemónico en términos mnémicos, puede cambiar sustancialmente en otro periodo dependiendo de las configuraciones sociales del presente. Para Zambrano, las necesidades actuales de las comunidades políticas son las que brindan las condiciones para la estructuración de la memoria colectiva, entendiendo que la memoria no es tradición e inmutabilidad sino devenir histórico. Así, «la memoria colectiva no es la transmisión de conocimientos de generación a generación, sino un proceso más complejo en la formación del sujeto, que está orientado a la construcción de su identidad colectiva» (Zambrano, 2006).

La memoria, entonces, no es una escatología, sino un producto cultural que construye a lo largo de la historia un grupo social, y que, así como ha servido como recurso de dominación, en determinadas situaciones puede servir como referente emancipatorio. En todo caso, la memoria colectiva es un intento por dar sentido a las condiciones (sociales, políticas, culturales) de un grupo en el presente, por lo cual su construcción tiene lugar en la intersubjetividad, es decir, en las negociaciones que se establezcan entre los diferentes miembros del grupo al definir qué se olvida y qué se recuerda. Para Passerini, «el silencio es esencial para recordar que la memoria no solamente es palabra, también es la 'memoria encarnada' [...] que toma forma en las relaciones intersubjetivas» (Passerini, 2003).

La pregunta por la manera en que los grupos construyen su memoria colectiva nos lleva a pensar no sólo en las disputas que tienen lugar dentro de un grupo social a la hora de establecer lo que debe hacer parte de la memoria o del olvido, sino, además, a entender cómo se "transmiten" estas formas de memoria y olvido a lo largo de la historia y las fracturas que se presentan en dicho proceso. Para Augè

[...] si admitimos la hipótesis según la cual nuestra relación con el tiempo pasa necesariamente por el olvido, no resultará tan sorprendente que ahora proponga una nueva hipótesis: la etnología, las teorías locales sobre el tiempo que esta disciplina ha recogido o reconstituido, los testimonios y las reflexiones que se han esforzado en recopilar, ponen en evidencia ejemplos de olvido de los que podrían afirmarse que poseen una virtud narrativa (que ayudan a vivir el tiempo como una historia) y que, en este sentido, constituyen, en términos de Paul Ricœur, configuraciones del tiempo (Augè, 1998). 
A pesar de reconocer la pertinencia de la memoria colectiva en determinados momentos históricos para algunos grupos sociales específicos, Candau propone una mirada más crítica sobre dicho proceso. En sus reflexiones, Candau distingue entre: 1) memoria de bajo nivel (protomemoria) caracterizada por lo circunstancial y cotidiano; esta memoria está relacionada con lo que Bourdieu denominaba habitus, es decir, con aquellos conocimientos incorporados por la experiencia diaria y que dan sentido al mundo práctico; 2) memorias de alto nivel, cercanas a los recuerdos y los reconocimientos; son la memoria propiamente dicha; y 3) metamemoria, entendida como el conocimiento que cada individuo tiene de su propia memoria y lo que dice de ella. Estas distinciones son posibles en la esfera individual; no obstante cuando se piensa en lo social, es más difícil aceptar dichas divisiones.

Generalmente se ha apelado al término de 'memoria colectiva' para referirse a la forma en que los grupos recuerdan. Para el autor,

[...] en su acepción corriente, la expresión 'memoria colectiva' es una representación. La memoria colectiva es una forma de metamemoria, es decir, un enunciado que los miembros de un grupo quieren producir acerca de una memoria supuestamente común a todos los miembros de ese grupo (Candau, 2001).

En todo caso, no es posible darle un carácter demasiado estable ni homogéneo a la memoria colectiva, pues se correría el riesgo de caer en lo que Candau llama las retóricas holistas, esto es totalizaciones que se hacen utilizando términos o expresiones que pretenden designar conjuntos homogéneos compuestos por elementos isomorfos. En esta dirección, el autor hace una crítica de la noción de memoria colectiva, pues, según él,

[...] por un lado es empíricamente imposible y por el otro es insustentable desde un punto de vista teórico, ya que esconde una triple confusión: una primera confusión entre los recuerdos manifestados (objetivados) y los recuerdos tal como son memorizados, una segunda confusión entre la metamemoria y la memoria colectiva, $y$ una última confusión entre el acto de memoria y

el contenido de ese acto (Candau, 2001).

La anterior idea sugiere una pista relacionada con la manera en que se construye narrativamente la memoria, es decir, por el lugar que ocupa la narración en la re-construcción de la memoria y las apuestas por la subjetividad que se juegan en la misma. En los análisis de Candau, cualquier intento por reconstruir la memoria colectiva a partir de los recuerdos manifestados por algunos actores sociales es reduccionista, pues deja en la sombra los recuerdos no manifestados. Sumado a lo anterior, puede ser que lo que se diga no sea, necesariamente, lo que pasó, sino que constituye aquellos relatos o recuerdos que se volvieron representaciones públicas por su 'contagio' entre los actores sociales.

Sarlo, por su parte, hace una fuerte crítica al recurso testimonial llamando la atención sobre el carácter de la tercera persona (testigo) en el mismo. En muchas ocasiones el pasado es reconstruido a partir del testimonio de personas que no vivieron en carne propia el fenómeno por recordar (por ejemplo, la shoah judía) sino que los presenciaron de lejos o a partir de la experiencia de terceros, de allí que sea necesario someterlo a un escrutinio ideológico. Compartiendo esta preocupación analítica de Sarlo, considero que es necesario reflexionar, además, sobre las formas de verdad que producen los testimonios, es decir, a qué intereses, a qué actores sociales benefician o no determinados testimonios. No se trata de un prurito de neutralidad o de objetividad, sino de profundizar en el análisis del carácter relacional (de disputa política) que tiene la memoria y, por supuesto, el testimonio que la reconstruye. En palabras de Sarlo,

Es cierto que la memoria puede ser un impulso moral de la historia y también una de sus fuentes, pero estos dos rasgos no soportan el reclamo de una verdad más indiscutible que las verdades que es posible construir con y desde otros discursos. Sobre la memoria no hay que fundar una epistemología ingenua cuyas pretensiones serían rechazadas en cualquier otro caso. No hay equivalencia entre el derecho a recordar y la afirmación de una verdad del recuerdo; tampoco el deber de 
memoria obliga a aceptar esa equivalencia [...] sólo una fetichización de la verdad testimonial podría otorgarles un peso superior al de otros documentos, incluidos los testimonios contemporáneos, a los hechos de los años sesenta y setenta. Sólo una confianza ingenua en la primera persona y en el recuerdo de lo vivido pretendería establecer un orden presidido por lo testimonial. Y sólo una caracterización ingenua de la experiencia reclamaría para ella una verdad más alta (Sarlo, 2005).

Aceptando este riesgo del testimonio como recurso metodológico, Arfuch propone valorar el carácter móvil que la memoria adquiere en la narratividad, lo cual permite considerarla no como un dato objetivo para el historiador (como un hecho social dado) sino como un conjunto de sentidos que los actores sociales le otorgan al pasado. Para esta autora, "el tiempo mismo se torna humano en la medida en que es articulado sobre un modo narrativo". En sus palabras,

Hablar de relato entonces [...] no remite solamente a una disposición de acontecimientos -históricos o ficcionales-, en un orden secuencial, a una ejercitación mimética de aquello que constituiría primariamente el registro de la acción humana, con sus lógicas, personajes, tensiones y alternativas, sino a la forma por excelencia de estructuración de la vida $\mathrm{y}$, por ende, de la identidad, a la hipótesis de que existe, entre la actividad de contar una historia y el carácter temporal de la experiencia humana, una correlación que no es puramente accidental, sino que presenta una forma de necesidad "transcultural" (Arfuch, 2002).

En esta misma dirección Vezetti sugiere que la memoria, entendida como un campo de problemas, no debe centrarse exclusivamente en la recuperación del pasado, sino concebirse como una dimensión abierta a la práctica de la inteligencia. En este plano la memoria tendría un doble componente: desde el entendimiento y desde una dimensión ética. Aquí es importante comprender que la memoria, como terreno de disputa, no sólo se tensiona por las rivalidades del presente, o por lo que desde el presente se quiere decir del pasado; en la lucha por la memoria también hay una aporía entre presente y pasado: si el presente es el pasado recordado, es decir, lo ausente percibido a través del recuerdo, el presente sería igualmente un recuerdo ausente. No obstante, nuestra experiencia nos muestra que el presente no está ausente, por lo cual el pasado tampoco debería estarlo. La memoria, entonces, nos puede decir tanto sobre el pasado en disputa, como sobre el presente que se disputará en tiempos posteriores. Retomando las palabras de Vezetti:

[...] un corte histórico produce efectos hacia el futuro tanto como hacia el pasado. Hacia el pasado porque no hay un recomienzo que no opere alguna recuperación de una memoria anterior, así sea para corregirla o para cancelarla. Hacia el futuro, porque encarna la promesa de un tiempo nuevo (Vezzetti, 2002).

Paralelo a los riesgos que conlleva la memoria en la reconstrucción del pasado desde el presente, hay algunos acuerdos en torno a la importancia de la misma, entendiéndola como un escenario de disputas en el presente. Es decir, si bien la construcción de la memoria tiene como materia prima hechos del pasado, este proceso está relacionado con la actividad social y política del presente. Es desde el presente que se hace una selección de olvidos y memorias, definiendo lo que un individuo o un grupo debe recordar.

\section{La memoria: arena de conflicto}

Teniendo en cuenta la dimensión temporal de la memoria y las disputas que ésta conlleva a la hora de hegemonizar determinados sucesos o narraciones del pasado, se puede sugerir que la memoria, antes que un dato fijo, es un terreno de luchas entre posiciones del presente que se inscriben en una serie de tensiones para definir qué se debe olvidar y qué debe ingresar en la memoria. En el trabajo coordinado por Elizabeth Jelin sobre el lugar de la memoria en las dictaduras del Cono Sur, se anota lo siguiente:

Siempre habrá otras historias, otras memorias e interpretaciones alternativas, en la resistencia, en el mundo privado, en las "catacumbas". Hay una lucha política activa acerca del sentido de lo ocurrido, pero también acerca del sentido de la memoria misma. El espacio de la memoria es 
entonces un espacio de lucha política, y no pocas veces esta lucha es concebida en términos de la lucha "contra el olvido": recordar para no repetir [...] Tanto en las conmemoraciones como en el establecimiento de los lugares de la memoria hay una lucha política cuyos adversarios principales son las fuerzas sociales que demandan marcas de memoria y quienes piden la borradura de la marca, sobre la base de una versión del pasado que minimiza o elimina el sentido de lo que los otros quieren rememorar (Jelin, 2002).

El trabajo de Jelin aporta unas pistas interesantes para pensar el tema de la memoria, en tanto terreno de disputas y tensiones del presente sobre el pasado. Por un lado, es clave pensar la(s) memoria(s) como procesos subjetivos anclados en marcas simbólicas $y$ materiales; $y$, por otro, reconocer el potencial de cambio histórico de la memoria, es decir, ser concientes de que al recurrir a la memoria se debe entender el lugar que le otorgan los grupos sociales a la misma. Esta idea confirmaría el análisis de Vezetti, para quien la memoria tiene una dimensión ética. Lo anterior nos conduce a pensar que el estudio de la memoria debe estar atento, por lo menos, a tres preguntas: qué se recuerda, quién recuerda y el cómo y cuándo se recuerda.

Estos cuestionamientos nos ponen frente a la importancia que cobra la subjetividad a la hora de pensar el tema de la memoria, no sólo porque ésta es un atributo natural y cultural del sujeto, sino además porque los sujetos se construyen en medio de tensiones mnémicas, es decir, en la lucha que se genera por instituir determinada memoria sobre pasado. Esta relación entre memoria y subjetividad es pensada por Sarlo en los siguientes términos:

El sujeto no sólo tiene experiencias sino que puede comunicarlas, construir su sentido y, al hacerlo, afirmarse como sujeto. La memoria y los relatos de memoria serían una 'cura' de la alienación y la cosificación. Si ya no es posible sostener una Verdad, florecen en cambio unas verdades subjetivas que aseguran saber aquello que, hasta hace tres décadas, se consideraba oculto por la ideología o sumergido en procesos poco accesibles a la introspección simple. No hay Verdad, pero los sujetos, paradójicamente, se han vuelto cognoscibles (Sarlo, 2005).

La dimensión comunicativa del sujeto señalada por Sarlo, devuelve importancia a la narración en tanto es mediante ella que un sujeto se posiciona frente al pasado. Así mismo, la narración no está expresando la vivencia individual con determinada situación, sino que es expresión de las formas en que un grupo social se relacionó con su presente y las rutas que utiliza para la re-construcción de su pasado. La siguiente reflexión de Jiménez nos puede ayudar a comprender esta idea:

Yo soy un relato. Mi narración se demora en una palabra de nacimiento lejano, y se fragmenta hoy en un prisma de ecos innumerables. Soy un relato, pero no de sentido único. Muchas voces intervinieron en mi narración. Muchos senderos son en ella transitados. Yo soy, además, un relato abierto. Sólo el cuerpo que me acoge conoce la certeza de su fin, que no es meta [...] Somos conciencia histórica porque somos memoria. Las voces narrativas no son simple confusión o ruido. Los relatos construyen sentidos, y los hombres viven en ellos (Jiménez, 1996).

Sin duda alguna, pensar en la memoria implica, entonces, pensar en las formas de narrar el pasado por parte de los sujetos. Quizás en nuestro tiempo, más que en décadas anteriores, el recurso narrativo se ha consolidado como una estrategia metodológica de alta significación para pensar la manera en que los sujetos construyen el pasado y se relacionan con él. No obstante, no se trata de convertir las narraciones en objetos de conocimiento, es decir, en datos empíricos susceptibles de un tratamiento 'científico' para acercarnos a una verdad sobre la realidad indagada. Contrario a ello, el objetivo es reconocer el potencial transformador de la narración y del lenguaje, o sea, el campo de posibilidades y potencialidades que una y otro tienen para los sujetos. En este punto, estamos de acuerdo con Zemelman cuando anota que «no se trata de apropiarse de contenidos transformables en objetos, sino de potenciar la capacidad del sujeto para colocarse ante las circunstancias y reconocer sus opciones de desenvolvimiento» (Zemelman, 2007). No lejana de este argumento, Arfuch asume la 
relación entre narración y memoria en los siguientes términos:

[...] la memoria es eminentemente narrativa y, en tanto narración, articula por definición temporalidades disyuntas, despliega caprichosamente los acontecimientos en el tiempo, enhebra imágenes circulares, construye los vericuetos de una trama, aventura lógicas ex post. En definitiva, pone en forma, que es también decir otorga sentido, a una historia entre otras posibles. Pero además, nada es igual antes o después de un relato, por más que éste haya sido 'repetido' muchas veces. La fuerza performativa de la memoria -su propiedad de instaurar una realidad que como tal no preexiste a su intervención- se articula al acontecimiento de su enunciación, momento único, singular, situado, definido en relación con otro, el destinatario, con un contexto, pero abierto a la iterabilidad de la cita, la posibilidad de otros contextos, la diferencia en la repetición (Arfuch, 2008).

Como vemos, el potencial de la narración para pensar la manera en que se construyen distintas memorias sobre un acontecimiento radica en el carácter creativo de la misma. Ninguna historia podrá contarse igual dos veces. Cada historia, cada narración, incluso de un mismo sujeto, trae consigo la impronta de la subjetividad hecha idea en un contorno de realidad específico. Apelar a la memoria implica, entonces, desprenderse de la intención de descubrir las causas del presente en el pasado y aceptar que, a lo sumo, mediante la investigación podemos acercarnos a las interpretaciones que los sujetos hacen del pasado dependiendo de sus relaciones emotivas con el mismo. Esta idea nos puede conducir a abandonar el razonamiento histórico tradicional según el cual toda causa antecede a un efecto; quizás deberíamos aventurarnos a pensar una realidad en donde el efecto antecede a la causa y, por ende, puede actuar como diáspora temporal constructora de múltiples pretéritos.

Otorgarle valor -simbólico, investigativo- a la narración implica reconocer una dimensión clave de la subjetividad y de la importancia de la memoria en la conformación de aquella, que radica no sólo en la toma de conciencia y en el potencial de emancipación para el sujeto, sino además en la recuperación emotiva del pasado, o mejor, en la reconstrucción de las emotividades del pasado. Para Rossi, la memoria

[...] se configurará, con fuerza cada vez mayor, como un medio para remontarse hacia imágenes olvidadas y sepultadas por el tiempo. La autobiografía ya no será $[\ldots]$ el relato de una formación intelectual. Será como en Rousseau y después de otros innumerables autores, el redescubrimiento de emociones, imágenes y sensaciones olvidadas (Rossi, 2003).

Un breve balance en torno a la memoria nos deja ver su importancia para la comprensión del pasado, entendido no como un cúmulo de hechos que se suceden unos a otros, sino como un juego dinámico de interpretaciones de la realidad. Así mismo, la memoria constituye un elemento importante a la hora de pensar dimensiones como la subjetividad y la identidad, sin las cuales sería muy difícil comprender el devenir de las sociedades contemporáneas. Sin embargo, como toda categoría analítica, conlleva unos riesgos relacionados con dos problemas fundamentales: la fuente testimonial como el principal recurso para la reconstrucción de la memoria y las dificultades -teóricas y empíricas- para la conformación de la memoria colectiva.

\section{El sujeto: entre la memoria y la acción colectiva}

La pregunta por la subjetividad se relaciona con el carácter trascendental de la existencia humana. En este sentido, no se trata sólo de cuestionar las relaciones entre lo individual y lo colectivo, sino, también, las potencialidades que tiene el sujeto en el tiempo, es decir, realizar una indagación por la capacidad de anticipación y proyección del ser humano en su interacción con otros. En esta concepción es necesario que el sujeto deje de ser visto desde las externalidades que lo determinan y más bien se le asuma como el lugar desde el cual mirar la realidad, lo cual implica reconocer la potencialidad transformadora que tiene el sujeto y las variadas relaciones que se establecen entre él y los 'contornos' en los cuales se auto-construye, sino además 
incluir una gama de interrogantes que comportan tanto lo afectivo y lo cognitivo como lo político y lo social de la experiencia humana. En esta dirección, Zemelman se pregunta:

¿Cómo hablar del hombre?, ¿cómo hacerlo desde el conjunto de sus facultades sin reducirse a sus descripciones, como también a sus simples vivencias, sino hablar de ellas para mostrarlas como las capacidades de las posibilidades? Tal vez problematizando la idea de sujeto en un conjunto desigual de apetencias, desde el ámbito de sus alegrías y pesares, que resultan del tumulto de ideas y ambiciones, logros y desengaños, de sus inquietudes y derrotas, de sus sueños y acciones, que van modelando al sujeto en un constante darse y no darse; según las circunstancias que lo rodean. De sus variantes formas de interacción con las circunstancias, de las preguntas que lo asaltan $y$, a veces, abruman, o bien desde la sensación de soledad o de multitud que lo embargan cuando lo abordamos en pensamiento, voluntad, sensaciones, percepciones, dudas y certezas (Zemelman, 2007).

Esta gama de cuestionamientos sugerida por Zemelman puede contextualizarse pensando en la potenciación del sujeto desde dos planos agonísticos: la acción colectiva, entendida como una puesta en movimiento de las subjetividades constituyentes, y la memoria, asimilada al movimiento de tales subjetividades en el tiempo.

En relación con el primer plano, podemos sugerir que en toda acción colectiva es posible encontrar registros relacionados con la subjetividad de los actores vinculados a la misma, es decir, las acciones colectivas pueden ser analizadas como un conjunto de experiencias, saberes, intenciones, intereses, contradicciones y posibilidades de transformaciones definidas por los sujetos sociales en un horizonte político y cultural específico. En este sentido, la subjetividad estaría cumpliendo, además de sus funciones cognitiva (proponiendo esquemas referenciales para comprender la realidad) y práctica (sugiriendo elementos en torno a los cuales los sujetos orientan su experiencia), con una función identitaria, es decir, «aportando los materiales desde los cuales individuos y colectivos definen su identidad y sus pertenencias sociales». Siguiendo con este razonamiento, Torres destaca cómo el sujeto social

[...] se constituye en la medida en que pueda generar una voluntad colectiva y desplegar un poder que le permita construir realidades con una direccionalidad consciente. El sujeto puede ser entendido como el colectivo que potencia las posibilidades de la historia desde sus prácticas. $\mathrm{Al}$ trascender el marco intersubjetivo, se entra en el escenario político donde se definen y se confrontan opciones de futuro viables (Torres, 2006).

He optado por denominar los planos de la acción colectiva y de la memoria como planos agonísticos, en la medida en que ellos están definidos por el conflicto; es decir, en cada uno se hacen apuestas políticas por el futuro y se ponen en juego significados sobre los contornos de realidad en los que se inscriben los sujetos. Así, el sentido otorgado a la realidad está en permanente construcción dado el carácter dinámico de las interacciones sociales. Aquí nos acercamos a los planteamientos de Melucci, quien sugiere la necesidad de

[...] volver a plantearse la acción social a partir del proceso por el cual su significado se construye en la interacción social [...] Son los actores sociales quienes producen el sentido de sus actos mediante las relaciones que entablan entre ellos. Pero la interacción nunca es un proceso completamente manifiesto, sino que depende del campo de oportunidades y constricciones que los actores observan y utilizan. La dominación y el poder no son realidades metafísicas que existan fuera de los juegos de los actores; son la expresión más sólida, permanente y desequilibrada de esos juegos (Melucci, 2002).

En relación con el segundo plano agonístico en el que se constituye el sujeto, el de la memoria, es claro que no existen memorias unívocas y globalizantes, sino que la memoria está marcada por la fragmentación. Siguiendo a Candau, «las memorias contemporáneas serían mosaicos sin unidad, hechos de ruinas de grandes memorias organizadoras que volaron en pedazos, de fragmentos compuestos, de restos divergentes, de huellas heterogéneas, de 
testimonios opuestos, de vestigios incoherentes» (Candau, 2001). Quizás esta fragmentación y atomización de la memoria sea una ventaja metodológica, antes que una dificultad, a la hora de pensar cómo los diferentes actores sociales del presente llenan de sentidos disímiles las experiencias y acciones colectivas del pasado.

En esta misma dirección, Ibarra y Tejerina encuentran en la memoria un espacio clave a la hora de pensar los procesos de conformación de los movimientos sociales, a los cuales ven como agrupaciones constituidas por «un conjunto de normas preestablecidas, provenientes de la sedimentación de una memoria y práctica histórica, y que formal o informalmente constituye una guía para la acción» (Ibarra y Tejerina, 1998). Este proceso de sedimentación estaría relacionado con la manera en que los grupos sociales construyen sus referentes mnémicos, pues, siguiendo a Casquete, «gran parte de lo que recordamos lo hacemos en tanto que miembros de grupos sociales $[\ldots]$ sin intercambio comunicativo no hay memoria colectiva, y sin memoria colectiva

\section{Bibliografía}

Arfuch, L. (2008). Crítica cultural entre política y poética. Buenos Aires: Fondo de Cultura Económica.

(2002). El espacio biográfico. Buenos Aires: Fondo de Cultura Económica.

Augè, M. (1998). Las formas del olvido. Barcelona: Gedisa.

Candau, J. (2001). Memoria e identidad. Buenos Aires: Ediciones del Sol.

Casquete, J. (2006). El poder de la calle. Ensayos sobre acción colectiva. Madrid: Centro de Estudios Políticos y Constitucionales.

Cruz, M. (2007). Cómo hacer cosas con recuerdos. Buenos Aires: Katz Editores.

Elias, N. (1995). Sociología fundamental. Barcelona: Gedisa.

Ibarra, P. y Tejerina, B. (eds.). (1998). Los movimientos sociales: transformaciones políticas y cambio cultural. Madrid: Editorial Trotta.

Jelin, E. (2002). Los trabajos de la memoria. Madrid: Siglo XXI. la construcción identitaria se presenta como una empresa castrada por un impedimento de considerable magnitud» (Casquete, 2006).

La memoria, entonces, resulta central a la hora de pensar los sujetos sociales y los procesos sociopolíticos y culturales en los cuales ellos se han constituido como tales, ya que

[...] la memoria no se define por su función consoladora, del todo inesencial. Su esencia consiste en ser condición de posibilidad para la existencia del pasado: dibujar la escena en la que el sujeto ha de actuar. En este sentido, el sujeto es un producto de la memoria (Cruz, 2007).

En síntesis, la acción colectiva y la memoria, entendidos como planos agonísticos en donde se juegan significados sobre el pasado y el presente, $y$ se ponen de manifiesto los intereses sobre el futuro, son escenarios indispensables para ampliar la comprensión sobre la forma en que se constituyen las subjetividades contemporáneas y sobre los horizontes de acción de nuestra época.

Jiménez, J. (1996). Memoria. Madrid: Tecnos.

Kornhauser, W. (1959). Aspectos políticos de la sociedad de masas. Buenos Aires: Amorrortu editores.

Laraña, E. (1999). La construcción de los movimientos sociales. Madrid: Alianza Editorial.

McAdam, D., McCarthy, J. y Zald, M. (1999). Movimientos sociales: perspectivas comparadas. Madrid: Ediciones Istmo.

Melucci, A. (2002). Acción colectiva, vida cotidiana y democracia. México: El Colegio de México.

Mouffe, C. (2005). Política y pasiones: las apuestas de la democracia. En L. Arfuch (comp.), Pensar este tiempo. Buenos Aires: Paidós.

Offe, C. (1996). Partidos políticos y nuevos movimientos sociales. Madrid: Editorial Sistema.

Olson, M. (1992). La lógica de la acción colectiva. México: Limusa.

Passerini, L. (2003). Memoria y utopía. La primacía de la intersubjetividad. Valencia: Universidad de Valencia. 
Rossi, P. (2003). El pasado, la memoria, el olvido. Buenos Aires: Ediciones Nueva Visión.

Rubio, A. (2004). Perspectivas teóricas en el estudio de los movimientos sociales. En Circunstancia ( $\mathrm{N}^{\circ} 3$ ). Madrid: Instituto Universitario de Investigación Ortega y Gasset, enero de 2004.

Sarlo, B. (2005). Tiempo pasado. Cultura de la memoria y giro subjetivo. Una discusión. Buenos Aires: Siglo XXI.

Serrano, R. y García, I. (2002). La identidad como anomalía o debilidad del razonamiento metodológico más que como paradigma alternativo para el estudio de la acción colectiva. En J. Robles (comp.), El reto de la participación. Movimientos sociales y organizaciones. Madrid: Editorial Mínimo Tránsito.

Smelser, N. (1995). Teoría del comportamiento colectivo. México: Fondo de Cultura Económica.

Tarrow, S. (1997). El poder en movimiento. Los movimientos sociales, la acción colectiva y la política. Madrid: Alianza.

Tejerina, B. (2002). Movimientos sociales y producción de identidades colectivas en el contexto de la globalización. En J. Robles (comp.), El reto de la participación. Movimientos sociales y organizaciones. Madrid: Editorial Mínimo Tránsito.

Thompson, E. (1981). Miseria de la teoría. Barcelona: Crítica.
Torres, A. (2007). Identidad y política de la acción colectiva. Organizaciones populares y luchas urbanas en Bogotá 1980-2000. Bogotá: Universidad Pedagógica Nacional.

(2006). Subjetividad y sujeto: perspectivas para abordar lo social y lo educativo. En Revista Colombiana de Educación ( No 50). Bogotá: Universidad Pedagógica Nacional, primer semestre de 2006.

Touraine, A. (1997). ¿Podremos vivir juntos? Buenos Aires: Fondo de Cultura Económica.

(1987). El regreso del actor. Buenos Aires: Eudeba.

Paidós.

(2005). Un nuevo paradigma. Barcelona:

Traverso, E. (2007). El pasado, instrucciones de uso. Historia, memoria, política. Madrid: Marcial Pons Ediciones Jurídicas y sociales.

Vezzetti, H. (2002). Pasado y presente. Buenos Aires: Siglo XXI.

Zambrano, C. (2006). Memoria colectiva y comunidad política. Bogotá: Universidad Nacional de Colombia.

Zemelman, H. (2007). El ángel de la historia: determinación y autonomía de la condición humana. Barcelona: Anthropos. 